\title{
HUBUNGAN TINGKAT PENGETAHUAN DENGAN KEPATUHAN BEROBAT DI KLINIK PROGRAM TERAPI RUMATAN METADON DI PUSKESMAS PARAKAN KABUPATEN TEMANGGUNG
}

\section{CORRELATION BETWEEN KNOWLEDGE LEVEL AND MEDIACTION ADHERENCE IN CLINIC OF METHADONE TREATMENT THERAPY PROGRAM OF PARAKAN PUBLIC HEALTH CENTER IN TEMANGGUNG DISTRICT}

\author{
Sari Dwi Martiani, Heni Lutfiyati, Tiara Mega K \\ Jurusan D3 Farmasi, Fakultas Ilmu Kesehatan Universitas Muhammadiyah Magelang \\ Jl. Mayjend Bambang Soegeng Mertoyudan,Magelang 56172 \\ Email:henilutfiyati@gmail.com
}

Submitted: 10-10-2015

Reviewed: 04-11-2015 Accepted: 09-05-2016

\begin{abstract}
ABSTRAK
Penyalahgunaan zat psiko aktif merupakan masalah yang sering terjadi di seluruh dunia, dan berhubungan dengan peningkatan mortalitas dan morbiditas. Salah satu program terapi substitusi ini adalah program terapi rumatan metadon. Permasalahan utamanya adalah sebagian besar pasien berhenti mengikuti suatu program sebelum mereka merasakan efek terapeutik dari program tersebut. Kepatuhan dalam mengkonsumsi obat harian merupakan fokus dalam mencapai derajat kesehatan pasien. Tujuan penelitian adalah untuk mengetahui hubungan antara tingkat pengetahuan dengan kepatuhan berobat di Klinik Program Terapi Rumatan Metadon (PTRM) di Puskesmas Parakan Kabupaten Temanggung. Metode penelitian cross sectional. Populasi dalam penelitian ini adalah semua pasien metadon di Puskesmas Parakan Kabupaten Temanggung. Sampel yang diambil dalam penelitian ini adalah semua pasien aktif metadon di Puskesmas Parakan Kabupaten Temanggung sebanyak 31 pasien. Analisis data dilakukan dengan uji korelasi menggunakan rumus Chi Square $\left(x^{2}\right)$. Hasil penelitian menunjukkan ada hubungan antara tingkat pengetahuan dengan kepatuhan berobat di Klinik Program Terapi Rumatan Metadon (PTRM) di Puskesmas Parakan Kabupaten Temanggung dengan $p$ value 0,001 , dengan tingkat pengetahuan responden pada kategori baik sebanyak 13 responden (42\%) dan kepatuhan berobat di Klinik Program Terapi Rumatan Metadon (PTRM) responden pada kategori patuh sebanyak 11 responden (35,5\%). Kesimpulan penelitian ini adalah ada hubungan antara tingkat pengetahuan dengan kepatuhan berobat di Klinik Program Terapi Rumatan Metadon (PTRM) di Puskesmas Parakan Kabupaten Temanggung.
\end{abstract}

Kata kunci: tingkat pengetahuan, kepatuhan berobat, Program Terapi Rumatan Metadon

\section{ABSTRACT}

Psycho active substance abuse is a common problem throughout the world, and it is associated with the increase of mortality and morbidity. One of substitution therapy program is methadone maintenance therapy program. The main problem is most of patients stop following the maintenance program before they feel the therapeutic effects of it. Compliance in taking daily medication is the focus in achieving the health status of patients. The research objective is to determine the relationship between the knowledge level with methadone maintenance therapy program in the public health center of Parakan, District of Temanggung. The research method was cross sectional approach. The population in this study were all patients of methadone maintenance therapy program in the public health centers of Parakan, District of Temanggung. Samples on this research were 31 patients and they 
are all active on methadone maintenance therapy program in the public health center of Parakan, District of Temanggung. Data analysis was performed using Chi Square $\left(\mathrm{x}^{2}\right)$ formula correlation test. The results show there is a relationship between knowledge level with methadone maintenance therapy program in the public health center of Parakan, District of Temanggung with $\mathrm{p}$ value 0.001 , with 13 respondents (42\%) are in a good level of knowledge category and methadone treatment in obidiance catagory is 11 respondents $(35.5 \%)$. It is concluded that there is a relationship between methadone maintenance therapy program in the public health center of Parakan, District of Temanggung.

Keywords: knowledge level, medication compliance, methadone treatment therapy program

\title{
PENDAHULUAN
}

Penyalahgunaan zat psiko aktif merupakan masalah yang sering terjadi di seluruh dunia, dan berhubungan dengan peningkatan mortalitas dan morbiditas. World Health Organization (WHO) telah mengidentifikasi penggunaan alkohol, tembakau,dan obat terlarang merupakan 20 faktor risiko tertinggi penyakit $($ Anonim, 2006 $)$. Data epidemiologi diperoleh dari berbagai penelitian epidemiologis yang dilakukan Badan Narkotika Nasional (BNN) bekerjasama dengan Pusat Penelitian Kesehatan UI (Puslitkes UI) pada tahun 2008 menunjukkan data estimasi 3.6 juta penduduk Indonesia berusia 15-64 tahun (1.99\% dari total penduduk Indonesia) menggunakan narkotika, alkohol, psikotropika, dan zat adiktif lainnya (disingkat NAPZA) secara teratur, di mana $31 \%$ dari kelompok ini atau sekitar 900,000 orang mengalami ketergantungan heroin dan lebih dari setengahnya adalah pengguna heroin suntik (Raharjo, 2011). Program pengurangan dampak buruk dari penularan narkotik suntik (harm reduction) mutlak diperlukan, salah satunya melalui program terapi subtitusi dengan metadon dengan menggunakan sediaan metadon cair dengan cara diminum. Hal ini dikenal dengan program terapi rumatan metadon (Anonim, 2010)

Hal tersebut dikenal sebagai Program Terapi Rumatan Metadon atau sering disingkat sebagai Program Terapi Rumatan Metadon (PTRM) dan di Indonesia adalah bagian dari upaya nasional untuk pengendalian dan pencegahan dampak buruk atau Harm Reduction (Anonim, 2010). Terapi metadon adalah salah satu terapi bagi pengguna heroin untuk mengatasi masalah yang ditimbulkannya dan program terapi metadon dilakukan dalam jangka panjang, karena itu disebut Program Terapi Rumatan Metadon (PTRM). Tujuannya untuk menurunkan risiko yang dibuat karena penggunaan heroin dan memperbaiki kualitas hidup. Selain itu tujuan program terapi rumatan metadon yaitu mengurangi risiko pecandu opiat melalui penggunaan heroin suntik, meningkatkan kepercayaan diri pecandu bahwa mereka mampu menjalani proses perubahan perilaku, dari perilaku pengguna berisiko menjadi kurang berisiko atau tidak berisiko (Anonim, 2012)

Permasalahan utamanya adalah sebagian besar pasien berhenti mengikuti suatu program sebelum mereka merasakan efek terapeutik dari program tersebut. Beberapa PRM di Amerika menunjukkan data bahwa 7\% hingga $64 \%$ akan meninggalkan PRM secara premature dalam enam bulan pertama. Hal ini berarti efek terapeutik program metadon hanya dapat dialami oleh beberapa pasien yang mampu bertahan pada program tersebut dalam jangka panjang (Anonim, 2012)

Kepatuhan dalam mengkonsumsi obat merupakan aspek utama dalam penanganan penyakit-penyakit kronis. Kepatuhan dalam mengkonsumsi obat harian merupakan fokus dalam mencapai derajat kesehatan pasien (Lailatulshifah, 2014)

Berdasarkan fenomena di atas maka peneliti tertarik untuk melakukan penelitian tentang hubungan tingkat pengetahuan dengan kepatuhan berobat di Klinik Program Terapi Rumatan Metadon (PTRM) di Puskesmas Parakan Kabupaten Temanggung.

\author{
METODE PENELITIAN \\ Jenis Penelitian \\ Penelitian ini merupakan penelitian cross sectional. \\ Definisi Operasional \\ 1. Pengetahuan
}


Pengetahuan merupakan hasil tahu dan ini terjadi setelah orang melakukan pengindraan terhadap suatu obyek tertentu, dari pengalaman dan penelitian terbukti bahwa perilaku yang didasari oleh pengetahuan akan lebih langgeng dari pada perilaku yang tidak didasari oleh pengetahuan.

Pengukuran pengetahuan dengan Kuesioner yang diadopsi dari kuesioner yang digunakan pada penelitian sebelumnya, yakni penelitian yang dilakukan oleh Tampubolon yang berjudul "Hubungan Pengetahuan, Sikap dan Dukungan Keluarga Pengguna Narkoba Suntik serta Kepatuhan Berobat ke Klinik Program Terapi Rumatan Metadon (PTRM) di Puskesmas Tanjung Morawa Kabupaten Deli Serdang dilakukan modifikasi dengan menambahkan butir pertanyaan dengan skala pengukuran ordinal dan kategori :

a. Baik apabila diperoleh jawaban benar $76-100 \%$

b. Cukup apabila diperoleh jawaban benar antara $56-75 \%$

c. Kurang apabila diperoleh jawaban benar $<56 \%$

2. Kepatuhan Pasien

Kepatuhan Pasien adalah ketaatan pasien pengguna metadon dalam mengikuti terapi metadon yang diberikan oleh petugas kesehatan sesuai dengan dosis dan cara yang tepat setiap hari.

Pengukuran tingkat kepatuhan dengan Kuesioner yang diadopsi dari kuesioner yang digunakan pada penelitian sebelumnya, yakni penelitian yang dilakukan oleh Tampubolon yang berjudul "Hubungan Pengetahuan, Sikap dan Dukungan Keluarga Pengguna Narkoba Suntik serta Kepatuhan Berobat ke Klinik Program Terapi Rumatan Metadon (PTRM) di Puskesmas Tanjung Morawa Kabupaten Deli Serdang dengan skala pengukuran nominal dan kategori :

a.Patuh jika jawaban ya dan data kunjungan (registrasi) pasien selama 1 bulan adalah $100 \%$ karena pasien harus hadir setiap hari di puskesmas tempat program terapi rumatan metadon (Anonim, 2013)

b. Tidak patuh jika jawaban tidak dan data kunjungan (registrasi) pasien selama 1 bulan adalah $<100 \%$

3. Pasien Pengguna Matadon

Pasien pengguna metadon adalah pengguna narkoba suntik yang menjalani terapi metadon yang datang setiap hari ke fasilitas kesehatan PTRM untuk mendapatkan terapi dari petugas kesehatan. (ICD-X)

4. Terapi Metadon adalah salah satu terapi bagi pengguna heroin untuk mengatasi masalah yang ditimbulkannya.

5. Program Terapi Rumatan Metadon adalah program yang mengalihkan pengguna heroin pada obat lain yang lebih aman.

\section{Populasi dan sampel}

Populasi dalam penelitian ini adalah semua pasien yang terdaftar dan mengikuti terapi rumatan metadon yaitu sebanyak 31 orang. Kabupaten Temanggung. Sampel dalam penelitian ini adalah semua pasien yang terdaftar dan masih mengikuti Program Terapi Rumatan Metadon di Puskesmas Parakan Kabupaten Temanggung sebanyak 31 pasien. Penelitian dilakukan di Puskesmas Parakan Kabupaten Temanggung pada bulan Maret 2015

\section{Instrumen dan metode pengumpulan data}

Instrumen penelitian yang digunakan dalam penelitian ini adalah kuesioner yang terdiri dari tingkat pengetahuan dan kepatuhan berobat dan pengumpulan data dalam penelitian ini menggunakan metode prospektif. Kuesioner tingkat pengetahuan dan tingkat kepatuhan dalam penelitian ini mengadopsi kuesioner yang digunakan pada penelitian sebelumnya, yakni penelitian yang dilakukan oleh Tampubolon yang berjudul "Hubungan Pengetahuan, Sikap dan Dukungan Keluarga Pengguna Narkoba Suntik serta Kepatuhan Berobat ke Klinik Program Terapi Rumatan Metadon (PTRM) di Puskesmas Tanjung Morawa Kabupaten Deli Serdang dan untuk kuesioner tingkat pengetahuan dilakukan modifikasi dengan menambahkan butir pertanyaan, Kuesioner tingkat pengetahuan yang digunakan diuji validitasnya dan diperoleh nilai $r$ hitung $>r$ tabel (0.632) sehingga kuesioner dapat digunakan sebagai instrument penelitian. Analisis data dilakukan dengan uji korelasi menggunakan rumus Chi Square $\left(x^{2}\right)$. 


\section{Analisis Data}

Analisis Univariat

Analisis univariat bertujuan untuk menjelaskan atau mendiskripsikan karakteristik setiap variabel penelitian, pada umumnya dalam analisis ini hanya menghasilkan nilai mean atau rata-rata, median dan standar deviasi dari tiap variabel (Notoatmodjo, 2012)

Dalam penelitian ini, dilakukan pada variabel tingkat pengetahuan dan variabel kepatuhan berobat di Klinik Program Terapi Rumatan Metadon dalam bentuk tabel distribusi. Rumus Prosentase :

$$
\begin{aligned}
\mathrm{P} & =\frac{f}{N} \times 100 \% \\
\mathrm{p} & =\text { Persentase } \\
\mathrm{f} & =\text { Jumlah responden pada kategori tertentu } \\
\mathrm{N} & =\text { Jumlah total responden }
\end{aligned}
$$

\section{Analisis Bivariat}

Analisis bivariat dilakukan terhadap 2 variabel yang diduga berhubungan atau berkorelasi . Dalam penelitian ini, Perhitungan menggunakan rumus Chi Square $\left(x^{2}\right)$. Metode Chi Kuadrat $\left(x^{2}\right)$ digunakan untuk mengevaluasi frekuensi yang diselidiki atau frekuensi hasil observasi (fo) dengan frekuensi yang diharapkan (fe) dari sampel apakah terdapat hubungan atau perbedaan yang signifikan atau tidak. Metode $x^{2}$ menggunakan data nominal (deskrit), data tersebut diperoleh dari hasil menghitung. Sedangkan besarnya nilai $x^{2}$ bukan merupakan ukuran derajad hubungan atau perbedaan . Rumus yang digunakan untuk menghitung $x^{2}$ yaitu :

$$
\chi^{2}=\sum \frac{\left(f_{0}-f_{e}\right)^{2}}{f e}
$$

Dengan keterangan:

$X^{2}=$ Chi Kuadrat

fo $=$ Frekwensi yang diobservasi

$\mathrm{fe}=$ Frekwensi yang diharapkan (Hidayat, 2011).

Selanjutnya untuk mengetahui harga chi kuadrat yang diperoleh dibandingkan dengan chi kuadrat tabel, hasil yang diperoleh akan dicari koefisien korelasi hasilnya signifikan atau tidak, sehingga berdasarkan harga chi kuadrat tabel dengan taraf kesalahan 5\% dan taraf kepercayaan 95\% dapat ditentukan yaitu :

1) Hipotesis kerja (Ha) diterima apabila chi kuadrat hitung > chi kuadrat tabel.

2) Hipotesis nol (Ho) diterima apabila chi kuadrat hitung < chi kuadrat tabel.

\section{HASIL DAN PEMBAHASAN}

\section{Karakteristik Responden}

Hasil penelitian berdasarkan karakteristik responden yang mengikuti Program Terapi Rumatan Metadon di Puskesmas Parakan Kabupaten Temanggung sebagaimana pada Tabel I dan Tabel II.

Tabel I. Umur pasien Terapi Rumatan Metadon di Puskesmas Parakan Kabupaten Temanggung

\begin{tabular}{lllll}
\hline No & Karakteristik & N & Mean & SD \\
\hline 1 & Umur & 31 & 29,39 & 4.44
\end{tabular}

Sumber : Data Primer, 2015

Tabel II. Jenis kelamin pasien Terapi Rumatan Metadon di Puskesmas Parakan Kabupaten Temanggung

\begin{tabular}{llccc}
\hline No & \multicolumn{2}{c}{$\begin{array}{c}\text { Karakteristik } \\
\text { Responden }\end{array}$} & F & \% \\
\hline 1 & Jenis & Laki-Laki & 31 & 100 \\
& Kelamin & Perempuan & 0 & 0 \\
\hline & & Total & 31 & 100 \\
\hline
\end{tabular}


Berdasarkan Tabel I dan II diatas menunjukkan hasil sebagian besar responden berumur $\geq 29$ tahun sebanyak 16 responden $(51,4 \%)$ dan semua responden berjenis kelamin laki-laki.

\section{Tingkat pengetahuan tentang Program Terapi Rumatan Metadon di Puskesmas Parakan Kabupaten Temanggung}

Hasil penelitian berdasarkan tingkat pengetahuan tentang Program Terapi Rumatan Metadon di Puskesmas Parakan Kabupaten Temanggung pada Tabel III.

Tabel III. Tingkat pengetahuan tentang Program Terapi Rumatan Metadon di Puskesmas Parakan Kabupaten Temanggung

\begin{tabular}{llcc}
\hline No & Kategori & Frekuensi & \% \\
\hline 1 & Baik & 13 & 42,0 \\
2 & Cukup & 9 & 29,0 \\
3 & Kurang & 9 & 29,0 \\
\hline & Jumlah & 31 & 100 \\
\hline
\end{tabular}

Sumber : Data Primer, 2015

Berdasarkan Tabel diatas menunjukkan hasil sebagian besar responden memiliki tingkat pengetahuan baik yaitu sebanyak 13 responden (42\%).

Hasil penelitian menunjukkan sebagian besar responden memiliki tingkat pengetahuan baik yaitu sebanyak 13 responden (42\%). Tingkat pengetahuan responden yang baik di Klinik Program Terapi Rumatan Metadon (PTRM) di Puskesmas Parakan Kabupaten Temanggung disebabkan karena dilakukan kegiatan penyuluhan kesehatan kepada pasien setiap 3 bulan sekali yang dilakukan dengan cara mengumpulkan pasien PTRM pada saat melakukan terapi di Puskesmas.

Hasil penelitian ini tidak sama dengan hasil penelitian Pratiwi (2013) yang menunjukkan hasil sebagian besar responden memiliki pengetahuan cukup. Pengetahuan adalah hasil penginderaan manusia, atau hasil tahu seseorang terhadap objek melalui indera yang dimilikinya (Notoatmodjo, 2007).

Pengetahuan dipengaruhi oleh faktor pendidikan formal dan pengetahuan erat hubungannya dengan pendidikan, karena pendidikan yang tinggi maka akan semakin luas pengetahuannya. Namun tidak berarti bahwa seseorang yang berpendidikan rendah mutlak berpengetahuan rendah. Pengetahuan seseorang tentang suatu objek mengandung 2 aspek, yaitu aspek positif dan negatif. Kedua aspek ini yang akan menentukan sikap seseorang semakin banyak aspek positif dan objek yang diketahui, maka akan menimbulkan sikap makin positif terhadap objek tertentu (Wawan dan dewi, 2010).

\section{Kepatuhan berobat di Klinik Program Terapi Rumatan Metadon (PTRM) di Puskesmas Parakan Kabupaten Temanggung}

Hasil penelitian berdasarkan kepatuhan berobat di Klinik Program Terapi Rumatan Metadon (PTRM) di Puskesmas Parakan Kabupaten Temanggung sebagaimana pada Tabel IV.

Tabel IV. Kepatuhan berobat di Klinik Program Terapi Rumatan Metadon (PTRM) di Puskesmas Parakan Kabupaten Temanggung

\begin{tabular}{clcc}
\hline No & Kategori & Frekuensi & $\%$ \\
\hline 1 & Patuh & 11 & 35,5 \\
2 & Tidak Patuh & 20 & 64,5 \\
\hline & Jumlah & 31 & 100 \\
\hline
\end{tabular}

Sumber : Data Primer, 2015

Berdasarkan Tabel IV menunjukkan hasil sebagian besar responden tidak patuh melakukan terapi rumatan metadon yaitu sebanyak 20 responden $(64,5 \%)$.

Hasil penelitian menunjukkan sebagian besar responden tidak patuh melakukan terapi rumatan metadon yaitu sebanyak 20 responden $(64,5 \%)$ dan sebanyak 11 responden $(35,5 \%)$ patuh melakukan terapi rumatan metadon. Faktor penyebab ketidakpatuhan responden dalam mengikuti program terapi rumatan metadon berdasarkan kuesioner tingkat kepatuhan sebagian besar karena kendala jarak rumah 
dengan Puskesmas jauh. Keterjangkauan pelayanan menurut Pratiwi (2013) adalah faktor yang mendukung berperilaku terhadap kepatuhan suatu program, pada penelitian ini yang dibahas adalah faktor jarak ke lokasi, yaitu jarak tempuh yang harus dilalui pasien untuk dapat sampai ke tempat pelayanan kesehatan. Berdasarkan hasil kuesioner tingkat kepatuhan faktor lain yang menyebabkan responden yang mengikuti terapi rumatan metadon di Puskesmas Parakan tidak patuh karena efek dari terapi metadon yang sebagian besar pasien mengeluh sering mengantuk/tidur, dan mengalami penurunan tenaga (lesu). Hal ini sesuai dengan teori Preston (2006) dalam Tampubolon (2012) yang menyatakan bahwa efek dari metadon yaitu menyebabkan perubahan "mood" yang tidak begitu kuat, tetapi masa kerjanya lebih panjang dibandingkan heroin, dapat mengontrol emosi, metadon juga dapat menyebabkan mengantuk/tidur, dapat juga menyebabkan mual/muntah, pernafasan terlalu kerap dan dalam, reflex batuk berkurang dan metadon dapat mengurangi segala bentuk sakit fisik. Selain itu, juga dapat menyebabkan terjadinya penurunan frekuensi atau tidak adanya menstruasi, penurunan rangsangan seksual, penurunan tenaga (lesu), rasa berat pada tangan dan kaki dan keinginan untuk memakan makanan yang manis-manis (Tampubolon, 2012).

Hasil penelitian ini sejalan dengan hasil penelitian (Tampubolon, 2012) yang menunjukkan hasil sebagian besar responden tidak patuh menjalani terapi rumatan metadon. Kepatuhan dalam mengkonsumsi obat adalah perilaku untuk mentaati saran-saran atau prosedur dari dokter tentang penggunaan obat, yang sebelumnya didahului oleh proses konsultasi antara pasien dan atau keluarga pasien sebagai orang kunci dalam kehidupan pasien dengan dokter sebagai penyedia jasa medis (Lailatulshifah, 2014).

Terapi metadon adalah salah satu terapi bagi pengguna heroin untuk mengatasi masalah yang ditimbulkannya (Anonim, 2012). Tujuan dari terapi rumatan metadon adalah menghentikan penggunaan napza, meningkatkan kesehatan pengguna Napza dengan menyediakan dan memberikan terapi ketergantungan Napza serta perawatan kesehatan umum, memberi ruang untuk menangani berbagai masalah lain di dalam hidupnya dan menciptakan jeda waktu dari siklus harian membeli dan menggunakan napza, meningkatkan kualitas hidup pengguna napza suntik baik secara psikologis, medis, maupun sosial, dan menurunkan angka kematian karena overdose dan menurunkan angka kriminalitas (Anonim, 2006 ${ }^{\mathrm{b}}$ )

Terapi rumatan metadon harus dilaksanakan dengan patuh, karena dengan menjalani terapi rumatan metadon secara patuh bermanfaat untuk mengembalikan kehidupan pengguna sehingga mendekati kehidupan normal, pasien yang menggunakan metadon dapat selalu terjangkau oleh petugas karena pemakaian metadon yang digunakan secara oral atau diminum langsung didepan petugas, pasien berhenti/mengurangi menggunakan heroin, pasien berhenti/mengurangi menggunakan jarum suntik sehingga penyebaran HIV/AIDS dapat berkurang, kesehatan fisik dan status gizi meningkat karena pola hidup yang teratur, metadon dapat membuat hubungan antara pasien dan keluarga menjadi lebih baik dan stabil, masa kerja dari metadon lebih panjang dibandingkan heroin atau putaw, harga dari metadon tidak mahal atau murah dibandingkan dengan heroin dan putaw, metadon bersifat legal sehingga pasien tidak merasa takut tertangkap oleh polisi, dan metadon juga dapat diikuti dan disertai konseling, perawatan medis, dan pertolongan lain (Tampubolon, 2010).

Ketidak teraturan terapi pasien yang kemudian menyebabkan naiknya tingkat depresi tersebut berawal dari rasa bosan pasien terhadap panjangnya rangkaian terapi rumatan metadon yang membutuhkan waktu lama, kemudian muncul perasaan ragu terhadap keberhasilan terapi rumatan metadon sehingga hal ini mendorong pasien untuk cenderung tidak teratur menjalankan terapi dan akhirnya kembali menggunakan heroin. Selain itu gejala ketergantungan akan lebih sering muncul karena ketidak teraturan terapi yang di jalankan pasien, dan mempengaruhi semangat pasien untuk kembali sembuh. Hal inilah yang mencetuskan kenaikan tingkat depresi pada pasien rumatan yang tidak teratur menjalankan terapi rumatan metadon (Kandouw, 2007). 
3. Hubungan antara tingkat pengetahuan dengan kepatuhan berobat di Klinik Program Terapi Rumatan Metadon (PTRM) di Puskesmas Parakan Kabupaten Temanggung

Tabel V. Hubungan antara tingkat pengetahuan dengan kepatuhan berobat di Klinik Program Terapi Rumatan Metadon (PTRM) di Puskesmas Parakan Kabupaten Temanggung

\begin{tabular}{|c|c|c|c|c|c|c|}
\hline \multirow{3}{*}{ No } & \multirow{3}{*}{$\begin{array}{l}\text { Kategori Tingkat } \\
\text { Pengetahuan }\end{array}$} & \multicolumn{4}{|c|}{ Kepatuhan } & \multirow{3}{*}{$\begin{array}{c}P \\
\text { value }\end{array}$} \\
\hline & & \multicolumn{2}{|c|}{ Patuh } & \multicolumn{2}{|c|}{ Tidak Patuh } & \\
\hline & & $\mathrm{f}$ & $\%$ & $\mathrm{f}$ & $\%$ & \\
\hline 1 & Baik & 10 & 90,9 & 3 & 15,0 & \\
\hline 2 & Cukup & 1 & 9,1 & 8 & 40,0 & 0.001 \\
\hline \multirow[t]{2}{*}{3} & Kurang & 0 & 0 & 9 & 45,0 & \\
\hline & Jumlah & 11 & 100 & 20 & 100 & \\
\hline
\end{tabular}

Berdasarkan Tabel $\mathrm{V}$ menunjukkan hasil dari 11 responden yang patuh melakukan terapi rumatan metadon sebagian besar dengan pengetahuan baik yaitu sebanyak 10 responden $(90,9 \%)$, sedangkan dari 20 responden yang tidak patuh melakukan terapi rumatan metadon sebagian besar berasal dari responden dengan tingkat pengetahuan kurang yaitu sebanyak 9 responden (45\%).

Hasil hitung hubungan tingkat pengetahuan dengan kepatuhan berobat di Klinik Program Terapi Rumatan Metadon (PTRM) di Puskesmas Parakan Kabupaten Temanggung dengan menggunakan rumus Chi Square diperoleh nilai $p$ value sebesar 0,001. Hal ini menunjukkan bahwa ada hubungan tingkat pengetahuan dengan kepatuhan berobat di Klinik Program Terapi Rumatan Metadon (PTRM) di Puskesmas Parakan Kabupaten Temanggung dan dengan demikian hipotesis nol ditolak dan hipotesis kerja diterima.

Hasil penelitian ini sama dengan hasil penelitian Tampubolon (2012) dan Pratiwi (2013) yang menunjukkan hasil ada hubungan antara pengetahuan dengan kepatuhan berobat terapi rumatan metadon. Mempunyai pengetahuan yang tinggi berarti mampu memahami manfaat, tujuan, kegunaan tentang pengobatan tersebut. Tingkat pengetahuan tidak hanya diperoleh secara teori tetapi juga melalui pengalaman dan pengetahuan pasien berobat terapi rumatan metadon sangat berpengaruh pada sikap untuk patuh berobat karena semakin tinggi pengetahuan yang dimiliki oleh pasien semakin tinggi pula kesadaran untuk patuh berobat terapi metadon (Pratiwi, 2013)

\section{KETERBATASAN PENELITIAN}

Penelitian ini terdapat beberapa keterbatasan penelitian antara lain :

1. Pengumpulan data dilakukan dengan menggunakan instrument kuesioner dimana keakuratan data yang diperoleh antara variabel-variabel yang diteliti sangat tergantung pada kejujuran dan keterbukaan responden serta kemampuan dari peneliti dalam menggali

2. Kerangka konsep ini hanya menghubungkan komponen-komponen yang diperkirakan terkait kepatuhan sebagai variabel terikat (independen), sehingga besar kemungkinan ada beberapa variabel lain yang belum masuk atau belum ikut dalam kerangka konsep.

\section{KESIMPULAN}

Berdasarkan hasil penelitian menunjukkan ada hubungan antara tingkat pengetahuan dengan kepatuhan berobat di Klinik Program Terapi Rumatan Metadon (PTRM) di Puskesmas Parakan Kabupaten Temanggung $p$ value sebesar 0,001.

\section{DAFTAR PUSTAKA}

Anonim, 2006, Validation of the Alcohol, Smoking and Substance Involvement Screening Test (ASSIST) and Pilot Brief Intervention: A Technical Report of Phase II Findings of the WHO ASSIST Project. Geneva, Switzerland: WHO Press.

Anonim, 2006 ${ }^{\mathrm{b}}$, Keputusan Menteri Kesehatan No. 567 Tahun 2006 mengenai Pedoman Pelaksanaan Pengurangan Dampak Buruk Narkotika, Psikotropika, dan Zat Adiktif (NAPZA). 
Anonim, 2010, Modul dan Kurikulum Pelatihan Program Terapi Rumatan Metadon (PTRM), Kemenkes RI, Jakarta

Anonim, 2012, Modul Pelatihan Program Terapi Rumatan Metadon (PTRM), Kemenkes RI, Jakarta.

Anonim, 2013, Peraturan Menteri Kesehatan Nomor 57 Tahun 2013 Tentang Pedoman Penyelenggaraan Program Terapi Rumatan Metadona, Kemenkes RI, Jakarta.

Hidayat, 2011, Metode Penelitian Kebidanan \& Teknik Analisis Data, Salemba Medika, Jakarta

Lailatul shifah, 2014, Kepatuhan Pasien Yang Menderita Penyakit Kronis dalam Mengkonsumsi Obat Harian diunduh dari http://fpsi.mercubuana-yogya.ac.id/wp-content/uploads/2012/06/NoorKepatuhan.pdf. pada 20 November 2014.

Notoatmodjo, 2007, Promosi Kesehatan dan Ilmu Perilaku, Rineka Cipta, Jakarta.: 140

Notoatmodjo, 2012, Metode Penelitian Kesehatan. Rineka Cipta, Jakarta

Pratiwi, 2013, Faktor Yang Berhubungan Dengan Kepatuhan Berobat Terapi Rumatan Metadon di Puskesmas Kassi Kassi Kota Makasar diunduh dari http://repository.unhas.ac.id/handle/123456789/9386. pada 20 November 2014.

Raharjo, 2011, Keefektifan Konseling untuk Menurunkan Skor Penggunaan NAPZA di Klinik Rumatan Metadon, Jurnal Kedokteran Indonesia, Volume 2, Nomor 1, Januari, 2011 : 51-57.

Tampubolon, 2012, Hubungan Pengetahuan, Sikap dan Dukungan Keluarga Pengguna Narkoba Suntik dengan Kepatuhan Berobat ke Klinik Program Terapi Rumatan Metadon (PTRM) di Puskesmas Tanjung Morawa Kabupaten Deli Serdang diunduh dari http://repository.usu.ac.id/handle/123456789/34 pada 20 November 2014.

Wawan dan Dewi, 2010, Pengetahuan, Sikap dan Perilaku Manusia, Nuha Medika, Yogjakarta: 42 